\title{
ESTIMASI DAYA DUKUNG PERAIRAN PESISIR KECAMATAN BANYUPUTIH UNTUK TAMBAK UDANG BERDASARKAN LAJU BIODEGRADASI LIMBAH
}

\author{
Estimation of Power Supporting Coastal Water of Banyuputih District For Shrimp Food \\ Based on Waste Biodegradation Rate
}

\author{
Abdul Muqsith ${ }^{1}$, Nuddin Harahab ${ }^{2}$, Mohammad Mahmudi ${ }^{3}$, Muhammad Fadjar ${ }^{3}$ \\ ${ }^{1}$ Program Pascasarjana, Fakultas Ilmu Perikanan dan Kelautan, \\ Universitas Brawijaya, Malang, Indonesia \\ ${ }^{2}$ Jurusan Sosial Ekonomi Perikanan, Fakultas Ilmu Perikanan dan Kelautan, \\ Universitas Brawijaya, Malang, Indonesia. \\ ${ }^{3}$ Jurusan Manajemen Sumberdaya Perairan, Fakultas Ilmu Perikanan dan Kelautan, \\ Universitas Brawijaya, Malang, Indonesia. \\ Email korespondensi: penulis: muqsithd@yahoo.com
}

\begin{abstract}
ABSTRAK
Penelitian ini dilaksanakan pada bulan Mei 2018 di wilayah pesisir Kecamatan Banyuputih Kabupaten Situbondo dengan tujuan mengestimasi luas lahan dan kapasitas produksi tambak udang yang dapat didukung oleh perairan pesisir Banyuputih berdasarkan laju biodegradasi limbah organik dalam bentuk Total Suspended Solid (TSS). Hasil penelitian menunjukkan bahwa luas tambak intensif (padat tebar $126 \mathrm{ekor} / \mathrm{m}^{2}$ ) yang dapat didukung perairan adalah 39,30 hektar dengan kapasitas produksi udang 739,72 ton /musim tanam, sedangkan untuk tambak semi intensif (padat tebar 25 ekor $/ \mathrm{m}^{2}$ ) adalah 313,98 hektar dengan kapasitas produksi udang maksimal sebesar 803,85 ton/musim tanam, dan untuk tambak tradisional plus (padat tebar 8 ekor/m2) adalah 743,14 hektar dengan kapasitas maksimal produksi udang sebesar 578,90 ton/musim tanam. Hasil simulasi dari ketiga teknologi budi daya udang (tradisional plus, semi intensif dan intensif), diperoleh kombinasi luas lahan tambak udang yang masih dalam batasan daya dukung lingkungan, yaitu: 5\% (37,16 hektar) untuk lahan tambak udang teknologi tradisional plus (8 ekor/m2), $50 \%$ (157 hektar) untuk tambak udang teknologi semi intensif ( 25 ekor $\left./ \mathrm{m}^{2}\right)$, dan 45\% (17,69 hektar) untuk lahan tambak udang teknologi intensif $\left(126 \mathrm{ekor} / \mathrm{m}^{2}\right)$.Total luas lahan dari ketiga kombinasi teknologi adalah 211 hektar dengan produksi udang sebesar 763,75 ton/musim tanam. Hasil penelitian ini dapat dijadikan acuan untuk pengembangan tambak udang secara berkelanjutan di wilayah studi.
\end{abstract}

Kata kunci: biodegraasi, limbah, tambak, udang,

\section{ABSTRACT}

This research was conducted in May 2018 in the coastal area of Banyuputih Subdistrict, Situbondo Regency with the aim of estimating the land area and production capacity of shrimp ponds that could be supported by Banyuputih coastal waters based on the rate of biodegradation of organic waste in the form of Total Suspended Solid (TSS). The results showed that the area of intensive ponds (stocking density of 126 birds / m2) that could be supported by waters was 39.30 hectares with shrimp production capacity of 739.72 tons / planting season, whereas for semi-intense ponds (stocking density of 25 birds / m2) was 313.98 hectares with maximum shrimp production capacity of 803.85 tons / planting season, and for tradsional plus ponds (8 ekeor / $\mathrm{m} 2$ stock density) is 
743.14 hectares with a maximum capacity of shrimp production of 578.90 tons / planting season. The simulation results of the three shrimp culture technologies (traditional plus, semi intensive and intensive), obtained a combination of shrimp farm area that is still within the limits of environmental carrying capacity, namely: 5\% (37,16 hekar) for traditional plus-tech shrimp farm land (8 tail / m2), 50\% (157 hectares) for semi-intensive technology shrimp farms (25 individuals / $\mathrm{m} 2$ ), and 45\% (17.69 hectares) for intensive technology shrimp farms (126 individuals / m2). Total land area of the third combination of technology is 211 hectares with shrimp production of 763.75 tons / planting season. The results of this study can be used as a reference for the development of sustainable shrimp ponds in the study area.

Keywords: bodegradation, waste, ponds, shrimp,

\section{PENDAHULUAN}

Kecamatan Banyuputih merupakan salah satu kecamatan yang terdapat di wilayah pesisir Kabupaten Situbondo dan mempunyai potensi perikanan budi daya yang cukup berkembang. Pemerintah Daerah Kabupaten Situbondo menjadikan wilayah pesisir Kecamatan Banyuputih sebagai salah satu kawasan sentra pengembangan perikanan budi daya. Kegiatan perikanan budi daya yang sudah dikembangkan saat ini yaitu budi daya tambak udang. Luas lahan tambak yang terdapat di wilayah pesisir Kecamatan Banyuputih 113 ha yang seluruhnya dikelola dengan menggunakan teknologi intensif. dari total luas lahan tambak intensif tersebut hanya $46 \%$ (39 ha) yang masih produktif sedangkan sisanya $54 \%$ (74 ha) merupakan lahan tambak yang sudah tidak produktif (Dinas Perikanan dan Kelautan Kabupaten Situbondo, 2013).
Budi daya udang dengan teknologi intensif merupakan kegiatan ekonomi yang sangat produktif dalam meningkatkan kesejahteraan masyarakat dan devisa negara, namun legitimasi keberlanjutannya ditentukan oleh dampak kerusakan lingkungan yang ditimbulkannya (Supraptono et al., 2008). Budi daya udang intensif menghasilkan limbah organik terutama berasal dari sisa pakan, feses, dan bahan-bahan terlarut, yang terbuang ke perairan dan secara signifikan mempengaruhi kualitas lingkungan pesisir (Johnsen et al., 1993). Karena itu, pengembangan tambak udang secara lestari harus memperhatikan dua aspek penting, yaitu kuantifikasi limbah tambak dan kemampuan perairan pesisir dalam menerima limbah tambak (Soewardi, 2002). Kuantifikasi limbah tambak udang meliputi penghitungan beban limbah yang dihasilkan dari suatu kegiatan budi daya tambak udang, sedangkan kuantifikasi kemampuan perairan pesisir adalah 
penghitungan kuantitatif beban limbah udang di wilayah pesisir Kecamatan maksimum yang dapat ditampung oleh perairan pesisir berdasarkan kapasitas Banyuputih.

Penelitian ini bertujuan untuk asimilasi. Beban limbah tambak udang mengestimasi luas lahan dan kapasitas yang masuk ke lingkungan perairan produksi tambak udang yang dapat pesisir, apabila melampaui kapasitas asimilasi perairan pesisir, maka akan mengakibatkan terjadinya degradasi kualitas lingkungan perairan pesisir.

Kegiatan budi daya tambak udang di wilayah pesisir Kecamatan Banyuputih pada saat ini dan pengembangannya ke depan, dapat berpotensi menimbulkan kerusakan terhadap lingkungan pesisir jika tidak dilakukan pengelolaan secara bertanggung jawab, dan pada akhirnya akan mengancam keberlanjutan sumberdaya perikanan budi daya tambak udang di wilayah tersebut. Untuk menjaga kelestarian budi daya tambak udang dan memperkecil penurunan kualitas lingkungan akibat beban limbah yang dihasilkan, maka jumlah atau luasan tambak udang yang dapat dibuka atau dikembangkan di wilayah pesisir harus disesuaikan dengan daya dukung lingkungan perairan wilayah pesisir. Oleh karena itu, penelitian tentang estimasi daya dukung lingkungan perairan untuk tambak udang berdasarkan laju biodegradasi limbah, penting dilakukan untuk menjaga keberlanjutan produktivitas perikanan budi daya tambak

\section{METODE PENELITIAN}

Penelitian dilaksanakan di wilayah pesisir Kecamatan Banyuputih Kabupaten Situbondo Provinsi Jawa Timur pada bulan Mei 2018 (Gambar 1).

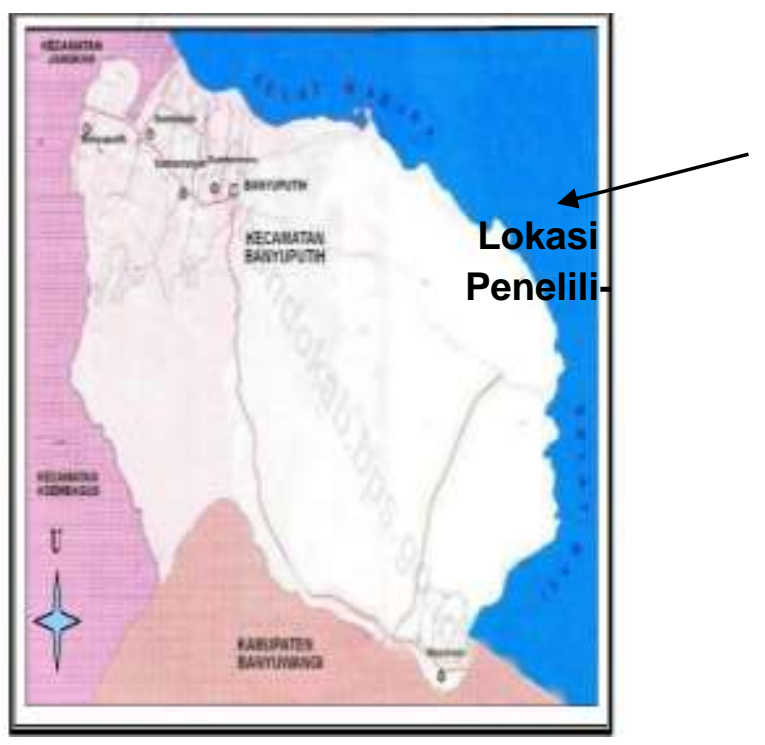

Gambar 1. Peta lokasi Penelitian

Kecamatan Banyuputih Kabupaten Situbodo dipilih sebagai lokasi peneltian dengan pertimbangan tersebut memiliki 
potensi yang cukup besar ntuk pengem- pasang surut dan frekwensi pasang surut bangan tambak udang dan kegiatan tambak yang ada di wilayah studi saat ini dan pengembangannya ke depan berpotensi dapat mendegradasi lingkungan perairan pesisir jika dalam pengembangannya tidak disesuaikan dengan daya dukung perairan dalam menerima limbah dari kegiatan tambak udang.

Jenis data yang digunakan dalam penelitian terdiri dari data primer dan data sekunder. Data primer dikumpulkan dengan cara pengukuran/pengamatan perairan pesisir Banyuputih, Kemiringan dasar perairan pesisir Banyuputih, Jarak dari garis pantai (saat pasang) hingga ke lokasi pengambilan air laut (sea water intake) untuk keperluan tambak udang. Sedangkan data sekunder diperoleh dari hasil penulusuran berbagai pustaka dan laporan hasil penelitian yang terkait dengan materi penelitian ini, meliputi data: panjang garis pantai pesisir Kecamatan Banyuputih, limbah tambak udang dan laju biodegradasi limbah.(Tabel 1) langsung di lapangan, meliputi: kisaran

Tabel 1. Jenis dan sumber data yag digunakan dalam penelitian

\begin{tabular}{lll}
\hline & Jenis data & Sumber data \\
\hline 1 & pasang surut air laut $(\mathrm{m})$ & Pengukuran langsung di lapangan \\
2 & Frekwensi Pasang surut (kali) & Pengukuran langsung di lapangan \\
3 & $\begin{array}{l}\text { Kemiringan dasar perairan pesisir } \\
\text { (derajad) }\end{array}$ & Pengukuran langsung di lapangan \\
4 & $\begin{array}{l}\text { Jarak dari garis pantai (saat pasang) } \\
\text { hingga ke lokasi pengambilan air laut (sea }\end{array}$ & Pengukuran langsung di lapangan \\
& $\begin{array}{l}\text { water intake) untuk keperluan tambak (m) } \\
\text { Panjang garis pantai kecamatan }\end{array}$ & Sukandar, et al (2016) \\
7. & $\begin{array}{l}\text { Banyuputih (m) } \\
\text { Laju biodegradasi limbah organik tambak } \\
\text { udang (mg/l) }\end{array}$ & Sitorus (2005) \\
Beban limbah oganik tambak udang & Alauddin (2010) \\
& udang intensif (kg /ton pdouksi udang & \\
\hline
\end{tabular}

Pengukuran pasang surut dilakukan untuk mendapatkan data perbedaan tinggi permukaan air laut pada saat pasang tertinggi dan surut terendah (data kisaran pasang surut) serta frekwensi pasang surut perairan pesisir Kecamatan Banyuputih Kabupaten Situbondo.
Pasang surut air laut diukur dengan menggunakan papan berskala, dilakukan selama 5 hari (5 x 24 jam). Sedangkan untuk data kemiringan dasar perairan, pengukuran dilakukan dengan menggunakan alat teodolit Nikon $302 \mathrm{se}$ ries total stations. Data jarak dari garis 
pantai (saat pasang) hingga ke lokasi pengambilan air laut (sea water intake) untuk keperluan tambak diukur dengan menggunakan alat bantu teodolit Nikon 302 series total stations dan Global Posittioning Systems (GPS)

Kuantifikasi volume badan air penerima limbah, mengacu pada formula dari Widigdo dan Pariwono (2003) sebagai berikut: dimana :

$$
V_{0}(m)^{3}=0,5 . h y\left(2 x-\frac{h}{\operatorname{tg} \theta}\right)
$$

$V_{0}=$ Volume air laut yang memasuki pesisir pada saat pasang $\left(\mathrm{m}^{3}\right)$

$$
h=\text { kisaran pasang surut setempat (m) }
$$

$y=$ panjang garis pantai $(\mathrm{m})$

$x=$ jarak dari garis pantai (saat pasang) hingga ke lokasi pengambilan air laut (sea water intake) untuk keperluan tambak (m)

$\theta=$ sudut kemiringan dasar perairan

Selanjutnya, untuk menentukan volume air tersisa ketika air surut $\left(\mathrm{V}_{\mathrm{s}}\right)$ dihitung dengan menggunakan rumus:

$$
V_{S}(m)^{3}=0,5 . h y\left(2 x-\frac{(2 h-1)}{\operatorname{tg} \theta}\right)
$$

Dengan demikian, volume air $(\mathrm{V} O s)$ yang tersedia di perairan pesisir dalam satu siklus pasang surut $(f)$ untuk mengecerkan limbah tambak menjadi:

$$
V_{0 s}(m)^{3}=0,5 . h y\left(4 x-\frac{(3 h-1)}{\operatorname{tg} \theta}\right)
$$

Jika diketahui frekwensi pasang surut sebesar $f$ kali dalam satu hari maka volume total air $\left(\mathrm{V}_{\text {tot }}\right)$ yang tersedia di perairan pesisir (volume badan air penerima limbah) adalah:

$$
V_{\text {tot }}(m)^{3}=f . V_{0 s}
$$

Selanjutnya hasil kuantifikasi volume toatal air yang tersedia di perairan pesisir (volume total badan air penerima limbah), data laju biodegradasi limbah organik tambak udang serta data beban limbah organik tambak udang intensif.di wilayah studi dijadikan acuan dalam mengestimasi daya dukung lingkungan perairan pesisir untuk pengembangan tambak udang intensif pada kawasan pesisir Banyuputih. Parameter beban limbah organik yang digunakan dalam penelitian ini adalah dalam bentuk Total Suspended Solid (TSS). Estimasi daya dukung lingkungan perairan mengacu pada formula Alauddin (2010):

$$
J L_{m}=V_{t o t} \times Y \times 10^{-6}
$$

dimana:

$J_{L m}=$ Jumlah limbah organik maksimum yang dapat ditampung perairan pesisir (ton/hari)

$V_{\text {tot }}=$ Volume total air yang tersedia di perairan pesisir $\left(\mathrm{m}^{3}\right)$

$Y \quad=$ Laju biodegradasi limbah organik tambak udang $(\mathrm{mg} / \mathrm{l})$ atau Y.10 ${ }^{-6}$ (ton $/ \mathrm{m}^{3} /$ hari) 
Jika diketahui jumlah limbah organik per ton produksi udang $=\mathrm{A}$, maka luas lahan tambak udang yang masih diperkenankan sesuai daya dukung lingkungan perairan adalah :

dimana:

$$
B=\frac{J L_{l m}}{A}
$$

$B=$ Luas tambak udang yang masih dierkenankan sesuai daya dukung lingkungan perairan pesisir (hektar)

$J_{L m}=$ Jumlah limbah organik maksimum yang dapat ditampung perairan pesisir (ton/hari)

$A=$ Jumlah limbah organik tambak udang ( $\mathrm{kg} /$ ton udang)

\section{HASIL DAN PEMBAHASAN}

Volume Total Air yang Tersedia di Perairan Pesisir untuk Proses Pengenceran Limbah

Hasil pengukuran pasang surut di lapangan selama 15 hari (15 x 24 jam) diperoleh data kiisaran pasang surut air laut perairan pesisir Banyuputih adalah $160 \mathrm{~cm}$ atau 1,6 $\mathrm{m}$ dengan frekwensi pasang surut 2 kali per hari. Jarak dari garis pantai (saat pasang) hingga ke lokasi pengambilan air laut (sea water intake) untuk keperluan tambak adalah $200 \mathrm{~m}$. Rata-rata sudut kemiringan pantai adalah $1^{0}$. Panjang garis pantai Kecamatan Banyuputih adalah $46,833 \mathrm{Km}$ atau 46.833 meter. (Sukandar et al, 2016). Karakteristik fisik perairan perairan pesisisr Kecamatan Banyuputih disajikan pada Tabel 2.

Tabel 2. Karakteristik fisik perairan pesisir Kecamatan Banyuputih Kabupaten Situbondo

\begin{tabular}{clcl}
\hline No. & \multicolumn{1}{c}{ Parameter } & Nilai & \multicolumn{1}{c}{ Sumber data } \\
\hline 1. & $\begin{array}{l}\text { Kisaran pasang surut permukaan air } \\
\text { laut }(h)\end{array}$ & $1,6 \mathrm{~m}$ & $\begin{array}{l}\text { Pengukuran langsung di } \\
\text { lapangan }\end{array}$ \\
2. & $\begin{array}{l}\text { Frekwensi pasang surut }(f) \\
\text { Pengamatan langsung di } \\
\text { lapangan }\end{array}$ \\
3. $\quad \begin{array}{l}\text { jarak dari garis pantai (saat pasang) } \\
\text { hingga ke lokasi pengambilan air laut } \\
\text { (sea water intake) untuk keperluan } \\
\text { tambak }(x)\end{array}$ & $200 \mathrm{~m}$ & $\begin{array}{l}\text { Pengukuran langsung di } \\
\text { lapangan }\end{array}$ \\
4. $\quad$ Rata-rata sudut kemiringan pantai $(\theta)$ & 10 & $\begin{array}{l}\text { Pengukuran langsung di } \\
\text { lapangan } \\
\text { Sukandar et al (2016) }\end{array}$ \\
\hline 5 & Panjang garis pantai $(\mathrm{y})$ & $46.833 \mathrm{~m}$ &
\end{tabular}

Sumber: Hasil survey (2018) 
Berdasarkan parameter pada Tabel udang intensif adalah $8,395 \mathrm{mg} / \mathrm{l} / \mathrm{hari}$.

2., maka dengan mengacu pada formula Widigdo dan Pariwono (2003) didapat hasil perhitungan sebagai berikut: volume badan air penerima limbah dalam satu siklus pasang surut adalah sebesar 21.599.149 $\mathrm{m}^{3}$. Frekwensi pasang surut perairan terjadi 2 kali dalam sehari. Dengan demikian maka volume total badan air penerima limbah di wilayah studi adalah sebesar 2 × 21.599.149 $\mathrm{m}^{3}=$ $43.198 .298 \mathrm{~m}^{3}$. Nilai hasil kuantifikasi volume total badan air penerima tersebut merupakan faktor penentu daya dukung lingkungan perairan pesisir dalam menerima limbah organik tambak udang di wilayah studi.

Estimasi Daya Dukung Perairan Pesisir Kecamatan Banyuputih Berdasarkan Laju Biodegradasi limbah Organik dalam Bentuk TSS

Seperti yang disampaikan sebelumnya, parameter limbah organik yang digunakan dalam penentuan daya dukung perairan dalam penelitian ini adalah dalam bentuk Total Suspended Solid (TSS). Hasil penelitian Sitorus (2005) mendapatkan laju biodegradasi limbah TSS tambak
Berdasarkan data tersebut, dan mengacu pada formula Alauddin (2010) maka jumlah maksimum limbah organik TSS tambak udang yang dapat ditampung oleh perairan pesisir Kecamatan Banyuputih adalah sebesar $43.198 .298 \mathrm{~m}^{3}$ × 8,395 $\mathrm{mg} / \mathrm{l} \times 10^{-6}=362,65$ ton/hari.

Budi daya udang vaname dengan teknologi intensif padat tebar $126 \mathrm{ekor} / \mathrm{m}^{2}$ dengan masa pemeliharan 110 hari ,FCR 1,47, produksi 18,825 ton udang/hektar menghasilkan limbah organik dalam bentuk TSS sebesar 9,229 ton/hektar. Tambak udang semi intensif padat tebar 25 ekor/ $\mathrm{m}^{2}$ dengan masa pemeliharaan 95 hari, FCR 1,31, produksi 2,557 ton udang/hektar, menghasilkan beban limbah organik dalam bentuk TSS sebesar 1,155 ton/hektar. Sedangakan pada budi daya udang teknologi tradisional plus padat tebar 8 ekor/m2 masa pemeliharaan 110 hari, produksi 0,779 ton udang/hektar, menghasilkan limbah organik dalam bentuk TSS sebesar 0,488 ton/ha (Alauddin, 2010). Berdasarkan data tersebut, maka daya dukung lingkungan perairan pesisir Kecamatan Banyuputih untuk pengembangan tambak udang dapat ditentukan (Tabel 3). 
Tabel 3. Daya dukung lingkungan perairan pesisir Banyuputih berdasarkan volume total badan air penerima limbah dan laju biodegradasi limbah organik tambak udang

\begin{tabular}{cccccc}
\hline $\begin{array}{c}\text { Teknologi } \\
\text { tambak } \\
\text { Udang }\end{array}$ & $\begin{array}{c}\text { Produksi } \\
\text { udang } \\
\text { (ton/ha) }\end{array}$ & $\begin{array}{c}\text { Jumlah } \\
\text { limbah } \\
\text { organik } \\
\text { (ton/ha) }\end{array}$ & $\begin{array}{c}\text { Daya tampung } \\
\text { limbah or- } \\
\text { ganik } \\
\text { perairan } \\
\text { pesisir } \\
\text { (ton/hari) }\end{array}$ & $\begin{array}{c}\text { Luas tam- } \\
\text { bak udang } \\
\text { sesuai daya } \\
\text { dukung } \\
\text { perairan } \\
\text { (ha) }\end{array}$ & $\begin{array}{c}\text { Kapasitas } \\
\text { produksi } \\
\text { masimal } \\
\text { sesuai daya } \\
\text { dukung } \\
\text { perairan } \\
\text { (ton) }\end{array}$ \\
\hline $\begin{array}{c}\text { Intensif } \\
(126 \text { ekor/m }\end{array}$ & 18,825 & 9,229 & 362,65 & 39,30 & 739,72 \\
,FCR 1,47) \\
$\begin{array}{c}\text { Semi Intensif } \\
(25 \text { ekor/m }\end{array}$
\end{tabular}

Sunber: Hasil analisis (2018)

Dari Tabel 3 dapat dijelaskan bahwa jika seluruh potensi lahan kawasan tambak udang di wilayah pesisir Kecamatan Banyuputih akan dimanfaatkan untuk tambak udang dengan teknologi intensif, maka luas lahan tambak intensif yang diperkenankan untuk dikembangkan sesuai batasan daya dukung lingkungan perairan adalah maksimal seluas 39,30 hektar dengan kapasitas produksi udang maksimal 739,72 ton/musim tanam. Jika potensi lahan tambak udang yang ada di wilayah pesisir Banyuputih seluruhnya akan dimanfaatkan untuk tambak udang dengan teknologi semi intensif (padat tebar 25 ekor $/ \mathrm{m}^{2}$ ), maka luas lahan yang diperkenankan untuk dikembangkan maksimal seluas 313,98 hektar dengan kapaitas

produksi udang maksimal sebesar 803,85 ton/musim tanam, dan jika seluruh potensi lahan tambak yang ada akan dimanfaatkan untuk tambak udang tambak tradsional plus (padat tebar $8 \mathrm{ekeor} / \mathrm{m}^{2}$ ), maka luas lahan tambak yang diperkenankna untuk dikembangkan adalah maksimal seluas 743,14 hektar dengan kapasitas maksimal produksi udang sebesar 578, 90 ton/musim tanam.

\section{Kombinasi Teknologi Budi daya} Udang Berdasarkan Daya Dukung Lingkungan Perairan Pesisir Banyuputih dalam Mendegradasi

\section{Limbah TSS}


Kombinasi luas tambak udang per sional plus intensif $\left.\left(8 \mathrm{ekor} / \mathrm{m}^{2}\right)\right)$ diperoleh teknologi budi daya didasarkan pada total kombinasi luas tambak udang dalam batalimbah organik TSS yang dihasilkan. san daya dukung perairan, yaitu 5\% untuk Serta kapasitas produksi tambak udang tambak udang tradsional plus $\left(8 \mathrm{ekor} / \mathrm{m}^{2}\right)$ pada kondisi daya dukung perairan. dengan luas lahan tambak 3,157 hektar; Jumlah limbah organik (TSS) mkasimal selanjutanya untuk tambak semi intensif pada batasan daya dukung perairan adalah (25 ekor/m $\mathrm{m}^{2}$ ) dengan luas lahan 157 sebesar 362,65 ton/hari, dengan kapasitas produksi untuk tambak udang tradisional hektar; dan untuk tambak intensif (126 $\mathrm{m}^{2}$ ) dengan luas lahan 17,69 hektar. Total plus $\left(8 \mathrm{ekor} / \mathrm{m}^{2}\right)$ adalah 578,90 luas lahan tambak optimal pada kawasan ton/musim tanam, untuk tambak udang pesisir Kecamatan Banyuputih yang semi intenstsif ( $25 \mathrm{ekor} / \mathrm{m}^{2}$ ) adalah 803,85 dapat dimanfaatkan untuk kegiatan tamton/musim tanam dan untuk tambak udang bak udang dengan kombinasi tiga intensf (126 ekor $/ \mathrm{m}^{2}$ ) adalah 739,72 teknologi (tradsional plus (8 ekor/m ${ }^{2}$ ) ton/musim tanam.

Hasil simulasi dari ketiga teknologi semi intensif $\left(25 \mathrm{ekor} / \mathrm{m}^{2}\right)$ dan intensif (126 ekor $/ \mathrm{m}^{2}$ ) adalah 211 hektar dengan budi daya udang (intensif $\left(126 \mathrm{ekor} / \mathrm{m}^{2}\right.$ ), produksi udang sebesar 763,75 ton udang semi intensif $\left(25 \mathrm{ekor} / \mathrm{m}^{2}\right)$ dan tradi- per musim tanam.

Tabel 4. Kombinasi teknologi berdasarkan daya dukung lingkungan perairan

\begin{tabular}{|c|c|c|c|c|c|c|c|c|}
\hline \multicolumn{2}{|c|}{$\begin{array}{l}\text { Tradisional plus } \\
(126 \text { ekor/m²) }\end{array}$} & \multicolumn{2}{|c|}{$\begin{array}{l}\text { Semi Intensif } \\
\left(25 \text { ekor } / \mathrm{m}^{2}\right)\end{array}$} & \multicolumn{2}{|c|}{$\begin{array}{c}\text { Intensif } \\
\left(126 \text { ekor } / \mathrm{m}^{2}\right)\end{array}$} & \multirow[t]{2}{*}{$\begin{array}{c}\text { Luas } \\
\text { tambak } \\
\text { (ha) }\end{array}$} & \multirow[t]{2}{*}{$\begin{array}{c}\text { Kapasitas } \\
\text { Produksi } \\
\text { Maksimal } \\
\text { (ton/MT) }\end{array}$} & \multirow[t]{2}{*}{$\begin{array}{c}\text { Total } \\
\text { Limbah } \\
\text { Organik } \\
\text { (kg/MT) }\end{array}$} \\
\hline $\begin{array}{c}\text { Presen- } \\
\text { tase }\end{array}$ & $\begin{array}{c}\text { Luas } \\
\text { (ha) }\end{array}$ & $\begin{array}{c}\text { Presen- } \\
\text { Tase } \\
\end{array}$ & $\begin{array}{l}\text { Luas } \\
\text { (ha) }\end{array}$ & $\begin{array}{c}\text { Presen- } \\
\text { Tase } \\
\end{array}$ & $\begin{array}{c}\text { Luas } \\
\text { (ha) }\end{array}$ & & & \\
\hline $100 \%$ & 743,14 & $0 \%$ & 0 & $0 \%$ & - & 743,14 & 578,90 & $356.707,20$ \\
\hline $0 \%$ & 0 & $100 \%$ & 313,98 & $0 \%$ & - & 313,98 & 803,85 & $362.646,90$ \\
\hline $0 \%$ & 0 & $0 \%$ & 0 & $100 \%$ & 39,30 & 39,30 & 739,72 & $362.699,70$ \\
\hline $85 \%$ & 631,67 & $10 \%$ & 31,40 & $5 \%$ & 1,97 & 665,04 & 609,45 & $357.600,76$ \\
\hline $75 \%$ & 557,34 & $15 \%$ & 47,10 & $10 \%$ & 3,93 & 608,37 & 628,65 & $358.197,41$ \\
\hline $65 \%$ & 483,04 & $20 \%$ & 62,80 & $15 \%$ & 5,90 & 551,74 & 648,02 & $358.524,02$ \\
\hline $55 \%$ & 408,73 & $25 \%$ & 78,50 & $20 \%$ & 7,86 & 495,09 & 667,30 & $359.390,63$ \\
\hline $45 \%$ & 334,41 & $30 \%$ & 94,19 & $25 \%$ & 9,83 & 438,43 & 686,60 & $359.987,24$ \\
\hline $35 \%$ & 260,10 & $35 \%$ & 109.89 & $30 \%$ & 11,79 & 381,78 & 705,89 & $360.583,85$ \\
\hline $25 \%$ & 185,79 & $40 \%$ & 125,60 & $35 \%$ & 13,76 & 325,15 & 725,17 & $361,180,46$ \\
\hline $15 \%$ & 111,47 & $45 \%$ & 141,30 & $40 \%$ & 15,72 & 268,49 & 744,46 & $361,777,07$ \\
\hline $5 \%$ & 37,16 & $50 \%$ & 157,00 & $45 \%$ & 17,69 & 211,85 & 763,75 & 362.373.68 \\
\hline $0 \%$ & 0 & $45 \%$ & 143,30 & $50 \%$ & 19,65 & 162,95 & 731,59 & 344.540 .96 \\
\hline
\end{tabular}

Hasil analisis (2018) 


\section{KESIMPULAN}

Kemampuan perairan pesisir Kecamatan Banyuputih dalam mendegradasii limbah organik dalam bentuk TSS adalah sebesar 362,65 ton/hari. Daya dukung lingkungan perairan berdasarkan laju biodegradasi limbah organic TSS adalah 39,30 hektar untuk tambak udang teknologi intensif (126 ekor/ $\left.\mathrm{m}^{2}\right)$, dengan kapasitas produksi udang 739,72 ton/musim tanam, sedangkan untuk teknologi semi intensif (25 ekor $/ \mathrm{m}^{2}$ ) adalah 313,98 hektar dengan kapasitas produksi udang 803,85 ton/musim tanam, dan untuk tambak udang

\section{UCAPAN TERIMA KASIH}

Dsampaikan ucapan terima kasih kepada seluruh pihak yang telah membantu dalam pelaksanaan penelitian ini. Semoga Allah membalas dengan kebaikan. Jazakumullah Khoiron Ahsanul Jaza

\section{DAFTAR PUSTAKA}

Alauddin, M.H.R., 2010. Optimasi pemanfaatan wilayah pesisir berbasis daya dukung bagi pengembangan budi daya tambak udang di Kecamatan Mangara Bombang Kabupaten Takalar Provonsi Selatan. (Disertasi). Institut Pertanian Bogor. Bogor

Dinas Kelautan dan Perikanan (DKP) Kabupaten Situbondo. 2013. Laporan Penyusunan dan Analisis Data
Potensi Kelautan dan Perikanan Kabupaten Situbondo. Situbondo

Johnsen, RI, O. Grahl-Nielsen dan B.T Lunesttad, 1993. Environmental Distribution on Organic Waste from Marine Fist Farm. Aquaculture, 118. 219-224

Sukandar, Harsindhi ,C.J., Handayani, M., Dewi, C.S.U., Maulana, A.W., Supriyadi, Bahroni.2016. Profil desa pesisir Provinsi Jawa Timur, Volume 1 (Utara Jawa Timur). Bidang Kelautan, Pesisir, dan Pengawasan. Dinas Perikanan dan Kelautan Provinsi Jawa Timur. Surabaya. Hal:113.

Supraptono TKP., Puspito DCL., Siswanto., Poniran, Suyoto, 2008. Optimalisasi produktivitas tambak idle melalui budi daya multispesies dengan system pemeliharaan parallel dan resirkulasi. Laporan Kegiatan Balai Besar Pengembangan Budi daya Air Payau Jepara. Tahun 2008. Hal:209-219)

Sitorus, H. 2005. Estimasi daya dukung lingkungan pesisir untuk pengembangan areal tambak berdasarkan Laju Biodegradasi limbah tambak di perairan pesisir Kabupaten Serang. (Disertasi). Sekolah Pascasarjana IPB, Bogor.

Soewardi, K., 2002. Pengelolaan Kualitas Air Tambak. Makalah dalam Seminar Penetapan Standar Kualitas Air Buangan Limbah. Ditjen Perikanan Budi daya . Jakarta.

Widigdo, B., Pariwono, 2003. Daya dukung pantai utara Jawa Barat untuk budi daya udang (Studi kasus di Kabupaten Subang, Teluk Jakarata dan Serang), Jurnal Ilmu- 
ilmu Perairan dan Perikanan Indonesia 1, 10-17. 